Article

\title{
Antimalarial Activity of 4-Metoxychalcones: Docking Studies as Falcipain/Plasmepsin Inhibitors, ADMET and Lipophilic Efficiency Analysis to Identify a Putative Oral Lead Candidate
}

\author{
Michael Eder de Oliveira ${ }^{1}$, Gisele Cenzi ${ }^{1}$, Renata Rachide Nunes ${ }^{1}$, Carla Regina Andrighetti ${ }^{2}$, \\ Denia Mendes de Sousa Valadão ${ }^{2}$, Cláudia dos Reis ${ }^{3}$, Cláudia Maria Oliveira Simões ${ }^{3}$, \\ Ricardo José Nunes ${ }^{4}$, Moacyr Comar Júnior ${ }^{1}$, Alex Gutterres Taranto ${ }^{1}$, Bruno Antonio \\ Marinho Sanchez ${ }^{2}$, Gustavo Henrique Ribeiro Viana ${ }^{1, *}$ and Fernando de Pilla Varotti ${ }^{1, *}$ \\ 1 Centro de Ciências da Saúde-UFSJ/Campus Centro-Oeste, CEP 35501-296, Divinópolis, MG, Brazil \\ 2 Instituto de Ciências da Saúde-UFMT/Campus Sinop, CEP 78557-267, Sinop, MT, Brazil \\ 3 Departmento de Ciências Farmacêuticas-UFSC/Campus Universitário Trindade, CEP 88040-900, \\ Florianópolis, SC, Brazil \\ 4 Departmento de Química-UFSC/Campus Universitário Trindade, CEP 88040-900, Florianópolis, \\ SC, Brazil
}

* Authors to whom correspondence should be addressed; E-Mails: viana@ufsj.edu.br (G.H.R.V.); varotti@ufsj.edu.br (F.P.V.); Tel.: +55-37-3221-1610 (G.H.R.V. \& F.P.V.);

Fax: +55-37-3221-1614 (G.H.R.V. \& F.P.V.).

Received: 20 September 2013; in revised form: 23 November 2013 / Accepted: 30 November 2013 / Published: 10 December 2013

\begin{abstract}
Herein, we report the antimalarial activity of nine 4-methoxychalcone derivatives 1a-i and an initial analysis of their ADMET properties. All compounds showed potent activity against the $P$. falciparum chloroquine-resistant clone $\mathrm{W} 2$, with $\mathrm{IC}_{50}$ values ranging from $1.96 \mu \mathrm{M}$ to $10.99 \mu \mathrm{M}$, with moderate or low cytotoxicity against the HeLa cell line. The compound $\mathbf{1 a}\left(\mathrm{IC}_{50}=2.06 \mu \mathrm{M}\right)$ had the best selectivity index (9.0). All the sulfonamide 4-metychalcone derivatives synthesized had cLogP values between 2 and 5 (mean value 3.79) and molecular weights (MWs) below 500. The substitution of the pyrrolidine group in $1 \mathbf{i}$ by a morpholine group in $1 \mathbf{a}$ reduced the cLogP value from 3.05 in compound 1i to 2.34 in compound 1a. Indeed, compound 1a had the highest LipE value. The binding free energy of compound 1a showed it to be the most optimal chalcone derivative for plasmepsin-2 $(-7.3 \mathrm{Kcal} / \mathrm{mol})$. The physicochemical properties and LipE analysis of the dataset allowed us to establish that compound 1a is the highest quality compound of the series and a potential oral lead candidate.
\end{abstract}


Keywords: 4-methoxychalcone; malaria; ADMET properties; LipE

\section{Introduction}

In 2010, there were an estimated 219 million cases of malaria, a global infectious disease, and it was responsible for 660,000 deaths [1]. The arsenal of antimalarial drugs is limited and currently the most effective treatment against the pathogenic agent Plasmodium falciparum includes artemisinin combination therapies (ACTs), although resistance to artemisinins has been reported in four countries of the South-East Asia region: Cambodia, Myanmar, Thailand and Vietnam [2,3].

The need for new antimalarial therapies has stimulated research into the search for synthetic molecules that are effective against acquired resistance to artemisinin derivatives and would result in promising antimalarial activity [4,5]. In this context, chalcones (1,3-diaryl-2-propen-1-ones), the bio-precursors of flavonoids, have been used as scaffolds for medicinal chemists for many years and chalcone analogs are associated with a broad range of biological activities, including antimalarial activity [6-9].

The antimalarial activity of chalcones is associated with inhibiting either plasmodial aspartate proteases or cysteine proteases [10]. Plasmodial aspartate and cysteine proteases are attractive targets for antimalarial therapy due to their role in the degradation of hemoglobin during erythrocytic parasite development [11]. In addition, the sulfonamide group and its derivatives have already shown antimalarial activity [12]. A recent strategy adopted in the search for new antimalarial drugs is the design of hybrids $[13,14]$.

One of the main challenges in the development of new antimalarial drugs is how to achieve a viable lead candidate with good pharmacokinetic properties: absorption, distribution, metabolism, excretion and toxicity (ADMET) [15].

It is well known that artemisinin derivatives act only for a short time and require frequent dosing to maintain efficacy [16]. Therefore, the search for artemisinin derivatives, as well new synthetic compounds with enhanced pharmaceutical properties, has received considerable attention [5]. Herein we report the antimalarial activity of 4-methoxychalcone derivatives 1a-i (Figure 1) [17], molecular docking studies and an initial analyses of their ADMET properties. This study led to the selection of a lead candidate with optimal oral absorption properties.

\section{Results and Discussion}

\subsection{Biological Activity}

The half maximal inhibitory concentration $\left(\mathrm{IC}_{50}\right)$ and the lethal drug concentration $\left(\mathrm{LC}_{50}\right)$ values determined for nine 4-metoxychalcone derivatives $\mathbf{1 a - i}$, are given in Table 1. All compounds showed potency against the $P$. falciparum chloroquine-resistant clone $\mathrm{W} 2$, with $\mathrm{IC}_{50}$ values ranging from $1.96 \mu \mathrm{M}$ to $10.99 \mu \mathrm{M}$. In parallel we tested the toxicity of the compounds against the HeLa cell line. All $\mathrm{LC}_{50}$ values were higher than the $\mathrm{IC}_{50}$ values. The compound 1a had the best selectivity index (9.0) and was advanced for more detailed physicochemical analysis. 
Figure 1. 4-Methoxychalcone derivatives 1a-i synthesized [17].<smiles>[R]S(=O)(=O)c1cc(/C=C/C(=O)c2ccccc2)ccc1OC</smiles><smiles></smiles>

1a<smiles>Clc1ccc(N[V])cc1</smiles><smiles>CN(C)[14CH3]</smiles>

1b<smiles>Clc1ccc(N[V])cc1Cl</smiles><smiles>CNc1ccccc1</smiles>

1c<smiles>CNc1ccc(OC)cc1</smiles><smiles>CCN(C)CC</smiles><smiles>NCc1ccccc1</smiles><smiles></smiles>

Table 1. In vitro antiplasmodial activity $\left(\mathrm{IC}_{50}\right)$, cytotoxicity $\left(\mathrm{LC}_{50}\right)$ and selectivity index (SI) of the 4-methoxychalconederivatives1a-i.

\begin{tabular}{cccc}
\hline Compound & $\mathbf{I C}_{\mathbf{5 0}}(\boldsymbol{\mu M})$ & $\mathbf{L C}_{\mathbf{5 0}}(\boldsymbol{\mu M})$ & SI \\
\hline $1 \mathrm{a}$ & $2.06 \pm 0.05$ & $18.58 \pm 1.26$ & 9.0 \\
$1 \mathrm{~b}$ & $5.79 \pm 0.12$ & $20.70 \pm 1.62$ & 3.6 \\
$1 \mathrm{c}$ & $2.03 \pm 0.28$ & $11.54 \pm 0.23$ & 5.7 \\
$1 \mathrm{~d}$ & $3.64 \pm 0.40$ & $11.07 \pm 1.96$ & 3.0 \\
$1 \mathrm{e}$ & $2.83 \pm 0.21$ & $10.49 \pm 2.27$ & 3.7 \\
$1 \mathrm{f}$ & $4.33 \pm 0.06$ & $18.97 \pm 0.43$ & 4.4 \\
$1 \mathrm{~g}$ & $10.99 \pm 0.57$ & $20.70 \pm 1.60$ & 1.9 \\
$1 \mathrm{~h}$ & $1.96 \pm 0.02$ & $9.42 \pm 2.09$ & 4.8 \\
$1 \mathrm{i}$ & $2.07 \pm 0.22$ & $9.18 \pm 1.51$ & 4.4 \\
$\mathrm{CQ}$ & $0.45 \pm 0.04$ & $>100$ & $>100$ \\
\hline
\end{tabular}

${ }^{\mathrm{a}}$ chloroquine

\subsection{Physicochemical Properties Analysis}

A recent antimalarial screening with 88 synthesized chalcones showed that the majority of the compounds were active in vitro against $P$. falciparum with low cytotoxicity. However, they lacked oral bioavailability due to poor ADMET properties [10]. Compounds that have become marketed oral drugs have physicochemical characteristics that favor drug absorption or permeability [18].

These findings prompted us to evaluate the physicochemical properties of our chalcone derivatives (Table 2) to identify compounds with optimal oral absorption properties and to guide future structural modifications in order to improve ADMET properties. 
Table 2. Physicochemical properties of 4-methoxychalcone derivatives 1a-i.

\begin{tabular}{|c|c|c|c|c|}
\hline Compound & Molecular Weight & $\mathrm{pIC}_{50}$ & cLog P & $\operatorname{LipE}^{a}$ \\
\hline $1 \mathrm{a}$ & 387.45 & 5.685 & 2.34 & 3.345 \\
\hline $1 b$ & 345.41 & 5.237 & 2.74 & 2.497 \\
\hline $1 \mathrm{c}$ & 393.46 & 5.692 & 3.87 & 1.822 \\
\hline $1 d$ & 423.48 & 5.439 & 3.74 & 1.699 \\
\hline $1 \mathrm{e}$ & 427.90 & 5.549 & 4.42 & 1.129 \\
\hline $1 \mathrm{f}$ & 462.35 & 5.364 & 4.98 & 0.384 \\
\hline $1 \mathrm{~g}$ & 387.49 & 4.959 & 4.83 & 0.129 \\
\hline $1 \mathrm{~h}$ & 407.48 & 5.707 & 4.17 & 1.537 \\
\hline $1 \mathrm{i}$ & 371.45 & 5.683 & 3.05 & 2.633 \\
\hline $\mathrm{CQ}^{\mathrm{b}}$ & 515.86 & 6.343 & 3.73 & 2.613 \\
\hline
\end{tabular}

${ }^{\mathrm{a}} \mathrm{LipE}=\mathrm{pIC} 50-\mathrm{cLog} \mathrm{P} ;{ }^{\mathrm{b}}$ chloroquine

There is a general consensus that the molecular properties of drug candidates, such as molecular weight and lipophilicity, are important ADMET properties [19]. Other properties such as solubility, clearance and volume of distribution are also important to consider in the profile of drug candidates [20]. In addition, the use of computational tools has contributed to improve drug design in order to attain more efficacious antimalarial activity [21,22].

To rationalize the drug discovery/development process and to guide the optimization from lead compound to successful drug candidate, rules for predicting dug-like physio-chemical properties have been introduced [23]. The Lipinski's 'Rule of Five' [24] as well as other parameters like lipophilic efficiency (LipE) [25] have been shown to be useful tools to aid in choosing oral drug candidates.

All the sulfonamide 4-methylchalcone derivatives synthesized had cLogP values between 2 and 5 (mean value 3.79) and molecular weights (MWs) below 500 (mean value 400.72). Gleeson et al. [26] suggested that compounds with a cLogP $<4$ and MWs below 400 Da have a more favorable ADMET profile. Figure 2 shows the distribution of cLogP versus MW for the nine synthesized compounds. Among them, five compounds ( 56\%) had a cLogP between 2 and 4 .

Figure 2. cLogP versus molecular weight distribution of synthesized 4-methoxychalcone derivatives.

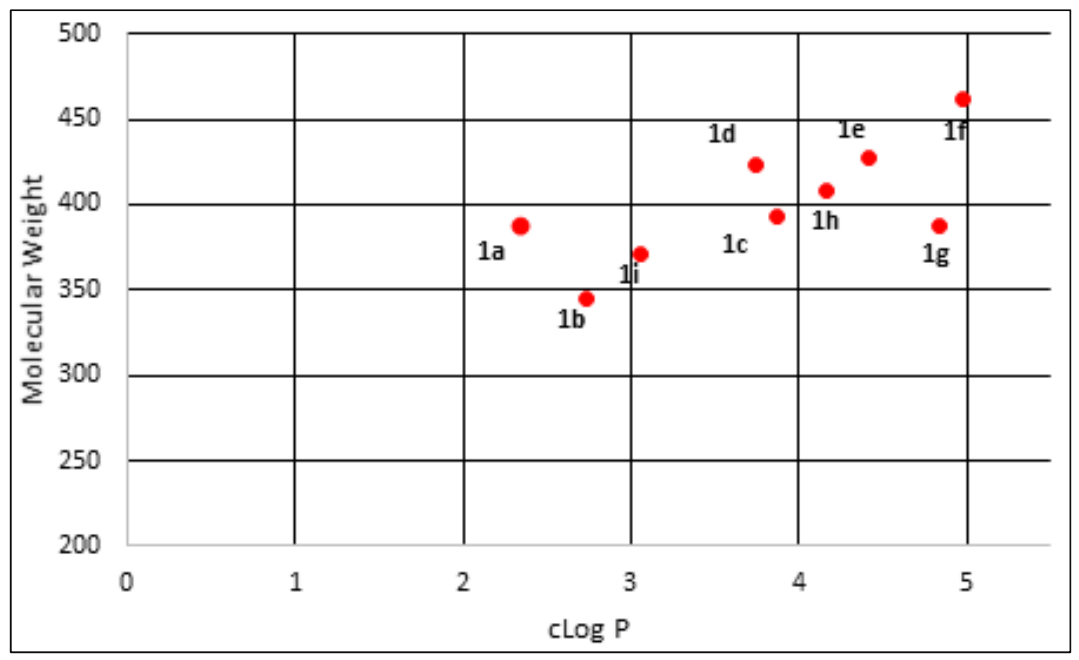


In addition to a range of lipophilicity and MW it is also desirable that drug candidates have high in vitro potency. High potency compounds reduce the chances that a drug will lack specificity for its target and allows the administration of smaller doses, thus reducing the risk of adverse effects [19].

Although in vitro potency and lipophilicity of compounds are important parameters to evaluate, the concept of Lipophilic Efficiency (LipE) aids in establishing a more balanced relationship between the potency observed in vitro and lipophilicity properties of evaluated chemical compounds [27]. Ryckmans et al. [19] reported that high quality lead compounds possess higher LipE values.

Plotting cLogP against $\mathrm{pIC}_{50}$ (Figure 3) for the nine sulfonamide 4-methylchalcone derivatives showed a distribution along lines of identical LipE values. Compounds $\mathbf{1 c}-\mathbf{h}$ have low LipE values (higher cLogP values).

Figure 3. cLogP versus $\mathrm{pIC}_{50}$ plot and LipE analysis.

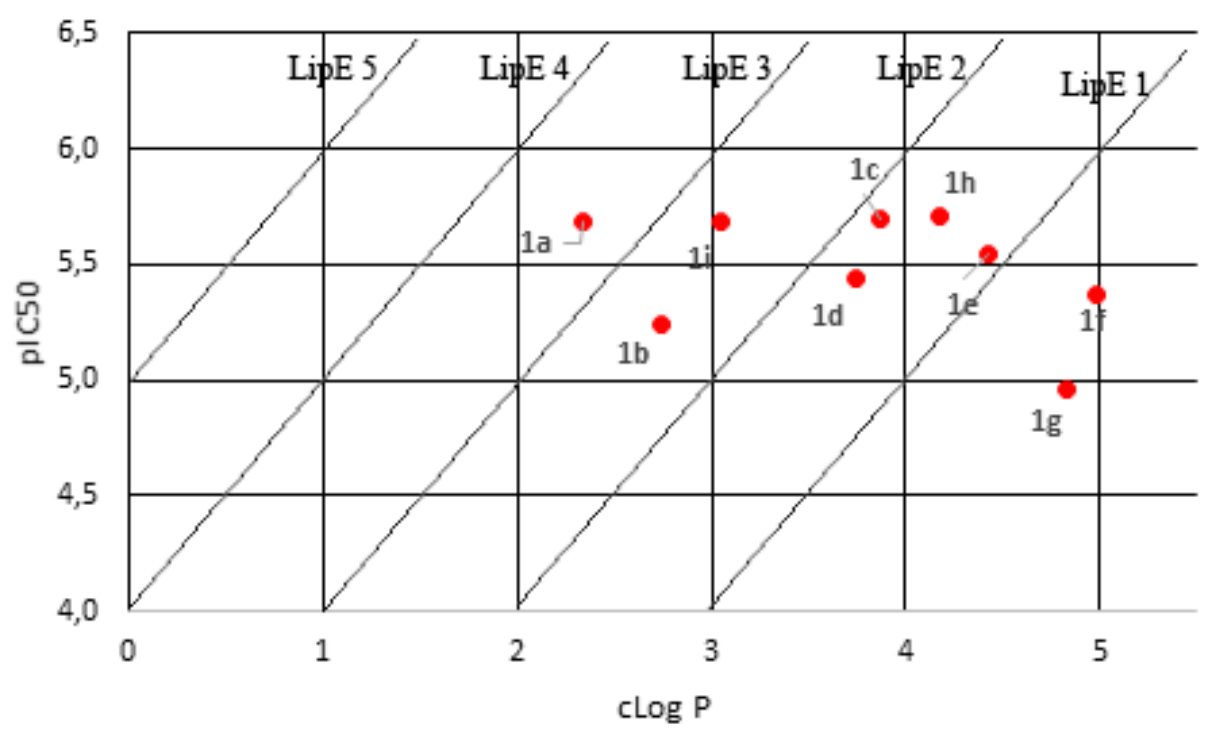

It is interesting to observe that substitution of the pyrrolidine group in 1i by a morpholine group in 1a had similar potency, but the cLogP value of compound 1i was reduced from 3.05 to 2.34 in compound 1a. Recent animal safety studies demonstrated that the risk of side effects/toxicity is reduced for compounds with cLogP below 3 [28]. In addition, this finding suggests that the presence of polar groups such as the oxygen atom of the morpholine ring may be important for the binding site interactions of compound 1a. Indeed compound 1a had the highest LipE value of the data set and was deemed to be the most optimal compound. The docking results also showed an additional binding interaction of compound 1a with the plasmepsins due the presence of a morpholine ring. This additional binding interaction of compound 1a with plasmepsin-2 is shown in Figure 4. In addition, docking results suggests a Michael reaction mechanism between these ligands and proteases. Figure 5 highlights a short distance (3.59 $\AA$ ) between the $\alpha, \beta$-unsaturated carbonyl moiety (Michael acceptor) of 1a and carboxylate anion (Michael donor) of Asp214, suitable for a nucleophilic attack resulting in an alkylation process [29]. 
Figure 4. Compound 1a docked into the plasmepsin-2 (PL-2) binding site, generated by AutoDock Vina and viewed by Discovery Studio Client (version 3.1.1.11157). Highlighting the H-bond with residue Thr217 and oxygen atom of the morpholin ring at the binding site (indicated by arrow).

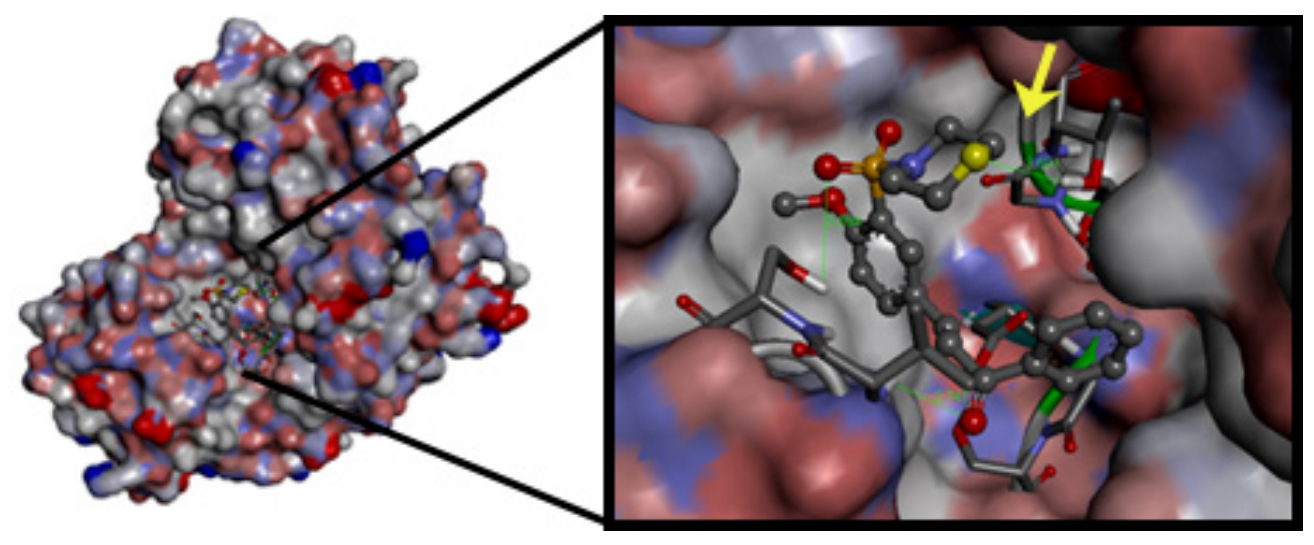

Figure 5. Compound 1a docked into the plasmepsin-2 (PL-2) binding site. Highlighting the the $\alpha, \beta$-unsaturated carbonyl moiety (Michael acceptor) and carboxylate anion (Michael donor) of Asp214.

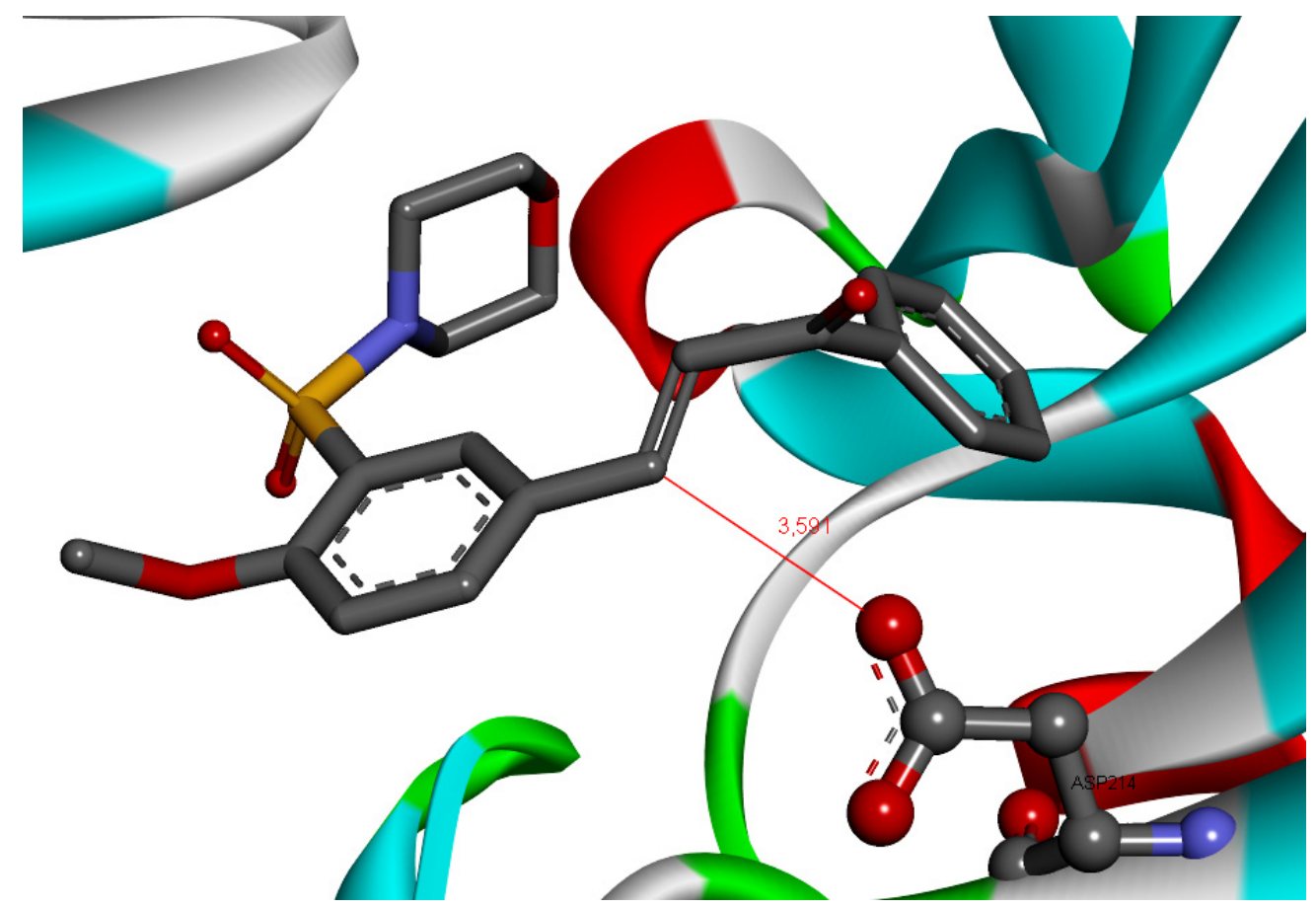

\subsection{Docking of 4-Metoxychalcone Derivatives to Falcipain-2, Plasmepsin-2, and Plasmepsin-4}

Chalcones have been reported to inhibit plasmodial aspartate proteases and cysteine proteases [10]. We therefore performed docking studies to determine the binding orientations of the 4-methoxychalcones at the active sites of amino acid residues of the enzymes falcipain-2, plasmepsin-2 and plasmepsin-4. The binding free energy of the docked compounds is given in Table 3.

The binding free energy of compound 1f, determined to be the most optimal chalcone derivative, for falcipain-2 $(-6.5 \mathrm{Kcal} / \mathrm{mol})$, plasmepsin-4 $(-7.6 \mathrm{Kcal} / \mathrm{mol})$ and plasmepsin-2 $(-8.5 \mathrm{Kcal} / \mathrm{mol})$ 
showed a better interaction for aspartic proteases (Figure 6), although, compound $\mathbf{1 f}$ does not exhibit the best physical chemistry parameters for oral administration (Table 3 ).

Table 3. Molecular docking of 4-metoxychalcone derivatives $\mathbf{1 a}-\mathbf{i}$ to falcipain-2, plasmepsin-2 and plasmepsin-4.

\begin{tabular}{llll}
\hline \multirow{2}{*}{ Compound } & \multicolumn{3}{l}{$\Delta$ G Energy $\left(\right.$ Kcal.mol $\left.^{-\mathbf{1}}\right)$} \\
\cline { 2 - 4 } & Falcipain-2 & Plasmepsin-2 & Plasmepsin-4 \\
\hline $\mathbf{1 a}$ & -4.9 & -7.3 & -6.9 \\
$\mathbf{1 b}$ & -5.5 & -7.2 & -7.0 \\
$\mathbf{1 c}$ & -6.2 & -8.0 & -7.4 \\
$\mathbf{1 d}$ & -6.1 & -7.8 & -7.3 \\
$\mathbf{1 e}$ & -6.1 & -8.0 & -7.5 \\
$\mathbf{1 f}$ & -6.5 & -8.5 & -7.6 \\
$\mathbf{1 g}$ & -5.5 & -6.6 & -6.2 \\
$\mathbf{1 h}$ & -5.0 & -7.7 & -6.9 \\
$\mathbf{1 i}$ & -5.5 & -7.1 & -7.1 \\
\hline
\end{tabular}

Figure 6. Compound 1f docked into the plasmepsin-2 (PL-2) binding site, generated by AutoDock Vina and viewed by Discovery Studio Client (version 3.1.1.11157). The $\alpha, \beta$-unsaturated ketone system of chalcones acts as a Michael acceptor with residue Asp241 at the binding site (indicated by arrow).

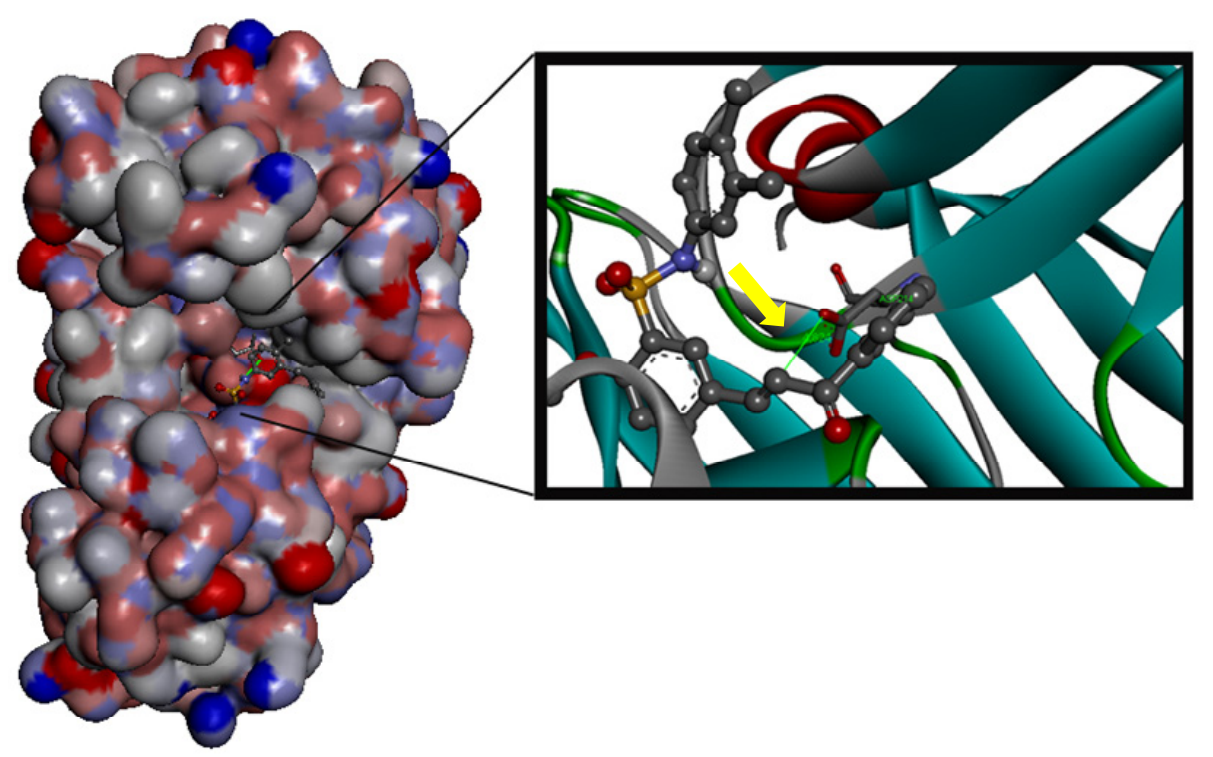

\section{Experimental}

\subsection{Drug Samples}

The compounds were stored at $-20{ }^{\circ} \mathrm{C}$ as $10 \mathrm{mg} / \mathrm{mL}$ stock solutions in dimethylsulfoxide (DMSO) (Sigma, St. Louis, MO, USA). The compounds were diluted in DMSO and used at a final concentration of $0.01 \%(\mathrm{v} / \mathrm{v})$. 


\subsection{Biological Assays}

\subsubsection{Plasmodium Falciparum Continuous Culture}

Human red blood cells infected with the P. falciparum clone W2 (chloroquine-resistant) were maintained in continuous culture as previously described [30,31]. The human red blood cells and plasma were ceded by the Fundação Hemominas-Hemonúcleo Divinópolis [32]. The synchronization of the parasites was achieved by sorbitol treatment [33] and parasitaemia was determined microscopically in Giemsa-stained smears.

\subsubsection{In vitro Antiplasmodial Activity}

The antimalarial effect of the synthetic 4-methoxychalone sulfonamide derivatives and the control compound chloroquine was measured using traditional methods [34] with minor modifications. Briefly, ring-stage parasites in sorbitol-synchronized blood cultures were added to 96-well culture plates with $2 \%$ parasitaemia and $2 \%$ haematocrit and then incubated with the test compounds. The compounds were diluted in complete media, from $10 \mathrm{mg} / \mathrm{mL}$ stock solutions in DMSO, at various concentrations $(0.1-30 \mu \mathrm{M})$. After $48 \mathrm{~h}$ incubation, Giemsa-stained blood smears were taken for microscopic evaluation of parasitaemia. All experiments were performed in triplicate. The results are expressed as the mean of the $\mathrm{IC}_{50}$ (the lethal drug concentration that reduced parasite viability by $50 \%$ ).

\subsubsection{Cytotoxicity Assay}

The cytotoxicity of the compounds was assessed with the HeLa human cell line (cervix adenocarcinoma ATCC\# CCl-2) using the MTT (3-(4,5-dimethylthiazol-2-yl)-2,5-diphenyltetrazolium bromide) (Sigma, St. Louis, MO, USA) colorimetric method. Briefly, the cells were plated in 96-well plates $\left(1 \times 10^{5}\right.$ cells/well $)$ and incubated for $24 \mathrm{~h}$ at $37{ }^{\circ} \mathrm{C}$ in a humidified atmosphere with $5 \% \mathrm{CO}_{2}$. After $24 \mathrm{~h}$, the wells were washed with culture medium (RPMI $+10 \%$ inactivated fetal calf serum $+2 \mathrm{mM}$ L-glutamine) and incubated with the compounds at various concentrations ( 0.05 to $500 \mu \mathrm{M})$. After $48 \mathrm{~h}$ incubation, the plates were treated with MTT. The colorimetric reading was performed in a microplate reader Spectramax M5e (Molecular Devices, Sunnyvale, CA, USA) at $550 \mathrm{~nm}$. Cytotoxicity was scored as the percentage reduction in absorbance versus untreated control cultures [35,36]. All experiments were performed in triplicate. The results are expressed as the mean of the LC50 (the lethal drug concentration that reduced cell viability by $50 \%$ ). The $\mathrm{IC}_{50}$ and $\mathrm{LC} 50$ values were calculated using OriginPro8.0 (OriginLab Corporation, Northampton, MA, USA) software. A selectivity index (SI), corresponding to the ratio between the cytotoxic and antiparasitic activities of each compound, was calculated as follows:

$$
\mathrm{SI}=\mathrm{LC}_{50} \mathrm{HeLa} / \mathrm{IC}_{50} \text { Plasmodium falciparum }
$$

\subsection{General Procedure of Docking}

Computational flexible docking and redocking was executed with the AutoDock Vina software. The docking procedure involved the preparation of the ligand and macromolecules using simulation boxes 
sufficiently large to involve the entire region of interaction between the ligand and receptor [37]. All compounds were docked to catalytic binding sites of falcipain-2 (PDB 3BPF), plasmepsin-2 (PDB 1LF3) and plasmepsin-4 (PDB 2ANL) to predict their binding modes and approximate binding free energies. The structures of all ligands were minimized using Gaussian09 software with PM6 method [38]. The lowest energy conformation was identified and binding energies were evaluated. cLogP values of the compounds was estimated using ChemBioDraw Ultra software version 12.0.

\subsection{Statistical Analysis}

The average $\mathrm{IC}_{50} \mathrm{~S}$ and $\mathrm{LC}_{50} \mathrm{~S}$ were compared using ANOVA. Difference between the values was evaluated using GraphPad Prism 5 Demo. Statistical significance was defined at the $5 \%$ level $(p<0.05)$.

\section{Conclusions}

All assayed compounds showed antimalarial activity. Among the nine compounds assayed there were four in the same potency range. The physicochemical and LipE analysis of the dataset allowed us to establish that compound 1a is the highest quality compound of the series. Molecular docking provided insight into the binding modes of compound 1a into the PL2 binding site. The data indicated that the presence of a morpholine ring as a substituent is required for optimal binding site interaction. Further optimization of this lead compound may provide a more potent and selective plasmepsin inhibitor potentially with better druggabilty.

\section{Acknowledgments}

This work was supported by the CNPq (Conselho Nacional de Desenvolvimento Científico e Tecnológico), FAPEMAT (Fundação de Amparo à Pesquisa do Estado de Mato Grosso) and FAPEMIG (Fundação de Amparo à Pesquisa do Estado de Minas Gerais) (Brazil). The authors are grateful to hemotherapy service of Fundação HemoMinas-Hemonúcleo Divinópolis for red blood cells and plasma supply.

\section{Conflicts of Interest}

The authors declare no conflict of interest.

\section{References and Notes}

1. World Health Organization. World Malaria Report 2011. Available online: http://www.who.int/malaria/publications/world_malaria_report_2012/report/en/index.html (accessed on 10 April 2013).

2. Phyo, A.P.; Nkhoma, S.; Stepniewska, K.; Ashley, E.A.; Nair, S.; McGready, R.; ler Moo, C.; Al-Saai, S.; Dondorp, A.M.; Lwin, K.M.; et al. Emergence of artemisinin-resistant malaria on the western border of thailand: A longitudinal study. Lancet 2012, 379, 1960-1966.

3. Carrara, V.I.; Lwin, K.M.; Phyo, A.P.; Ashley, E.; Wiladphaingern, J.; Sriprawat, K.; Rijken, M.; Boel, M.; McGready, R.; Proux, S.; et al. Malaria burden and artemisinin resistance in the mobile 
and migrant population on the thai-myanmar border, 1999-2011: An observational study. PLoS Med. 2013, 10, e1001398.

4. Hartwig, C.L.; Lauterwasser, E.M.; Mahajan, S.S.; Hoke, J.M.; Cooper, R.A.; Renslo, A.R. Investigating the antimalarial action of 1,2,4-trioxolanes with fluorescent chemical probes. J. Med. Chem. 2011, 54, 8207-8213.

5. Miller, L.H.; Ackerman, H.C.; Su, X.Z.; Wellems, T.E. Malaria biology and disease pathogenesis: Insights for new treatments. Nat. Med. 2013, 19, 156-167.

6. Bandgar, B.P.; Gawande, S.S.; Bodade, R.G.; Totre, J.V.; Khobragade, C.N. Synthesis and biological evaluation of simple methoxylated chalcones as anticancer, anti-inflammatory and antioxidant agents. Bioorg. Med. Chem. 2010, 18, 1364-1370.

7. Da Silva, G.D.; da Silva, M.G.; Souza, E.M.; Barison, A.; Simões, S.C.; Varotti, F.P.; Barbosa, L.A.; Viana, G.H.; Villar, J.A. Design and synthesis of new chacones substituted with azide/triazole groups and analysis of their cytotoxicity towards hela cells. Molecules 2012, 17, 10331-10343.

8. Sashidhara, K.V.; Avula, S.R.; Palnati, G.R.; Singh, S.V.; Srivastava, K.; Puri, S.K.; Saxena, J.K. Synthesis and in vitro evaluation of new chloroquine-chalcone hybrids against chloroquine-resistant strain of plasmodium falciparum. Bioorg. Med. Chem. Lett. 2012, 22, 5455-5459.

9. Yadav, N.; Dixit, S.K.; Bhattacharya, A.; Mishra, L.C.; Sharma, M.; Awasthi, S.K.; Bhasin, V.K. Antimalarial activity of newly synthesized chalcone derivatives in vitro. Chem. Biol. Drug Des. 2012, 80, 340-347.

10. Tadigoppula, N.; Korthikunta, V.; Gupta, S.; Kancharla, P.; Khaliq, T.; Soni, A.; Srivastava, R.K.; Srivastava, K.; Puri, S.K.; Raju, K.S.; et al. Synthesis and insight into the structure-activity relationships of chalcones as antimalarial agents. J. Med. Chem. 2013, 56, 31-45.

11. Moura, P.A.; Dame, J.B.; Fidock, D.A. Role of plasmodium falciparum digestive vacuole plasmepsins in the specificity and antimalarial mode of action of cysteine and aspartic protease inhibitors. Antimicrob. Agents Chemother. 2009, 53, 4968-4978.

12. Agrawal, V.K.; Srivastava, R.; Khadikar, P.V. Qsar studies on some antimalarial sulfonamides. Bioorg. Med. Chem. 2001, 9, 3287-3293.

13. Sharma, N.; Mohanakrishnan, D.; Shard, A.; Sharma, A.; Saima; Sinha, A.K.; Sahal, D. Stilbene-chalcone hybrids: Design, synthesis, and evaluation as a new class of antimalarial scaffolds that trigger cell death through stage specific apoptosis. J. Med. Chem. 2012, 55, 297-311.

14. Guantai, E.M.; Ncokazi, K.; Egan, T.J.; Gut, J.; Rosenthal, P.J.; Bhampidipati, R.; Kopinathan, A.; Smith, P.J.; Chibale, K. Enone- and chalcone-chloroquinoline hybrid analogues: In silico guided design, synthesis, antiplasmodial activity, in vitro metabolism, and mechanistic studies. J. Med. Chem. 2011, 54, 3637-3649.

15. Lipinski, C.A. Drug-like properties and the causes of poor solubility and poor permeability. J. Pharmacol. Toxicol. Method. 2000, 44, 235-249.

16. White, N.J. Qinghaosu (artemisinin): The price of success. Science 2008, 320, 330-334.

17. Andrighetti-Fröhner, C.R.; de Oliveira, K.N.; Gaspar-Silva, D.; Pacheco, L.K.; Joussef, A.C.; Steindel, M.; Simões, C.M.; de Souza, A.M.; Magalhaes, U.O.; Afonso, I.F.; et al. Synthesis, biological evaluation and sar of sulfonamide 4-methoxychalcone derivatives with potential antileishmanial activity. Eur J. Med. Chem. 2009, 44, 755-763. 
18. Abad-Zapatero, C.; Metz, J.T. Ligand efficiency indices as guideposts for drug discovery. Drug Discov. Today 2005, 10, 464-469.

19. Ryckmans, T.; Edwards, M.P.; Horne, V.A.; Correia, A.M.; Owen, D.R.; Thompson, L.R.; Tran, I.; Tutt, M.F.; Young, T. Rapid assessment of a novel series of selective $\mathrm{cb}(2)$ agonists using parallel synthesis protocols: A lipophilic efficiency (lipe) analysis. Bioorg. Med. Chem. Lett. 2009, 19, 4406-4409.

20. Meanwell, N.A. Improving drug candidates by design: A focus on physicochemical properties as a means of improving compound disposition and safety. Chem. Res. Toxicol. 2011, 24, 1420-1456.

21. Aguiar, A.C.; Santos, R.E.M.; Figueiredo, F.J.; Cortopassi, W.A.; Pimentel, A.S.; França, T.C.; Meneghetti, M.R.; Krettli, A.U. Antimalarial activity and mechanisms of action of two novel 4-aminoquinolines against chloroquine-resistant parasites. PLoS One 2012, 7, e37259.

22. Penna-Coutinho, J.; Cortopassi, W.A.; Oliveira, A.A.; França, T.C.; Krettli, A.U. Antimalarial activity of potential inhibitors of plasmodium falciparum lactate dehydrogenase enzyme selected by docking studies. PLoS One 2011, 6, e21237.

23. Hann, M.M.; Keserü, G.M. Finding the sweet spot: The role of nature and nurture in medicinal chemistry. Nat. Rev. Drug Discov. 2012, 11, 355-365.

24. Lipinski, C.A.; Lombardo, F.; Dominy, B.W.; Feeney, P.J. Experimental and computational approaches to estimate solubility and permeability in drug discovery and development settings. Adv. Drug Deliv. Rev. 2001, 46, 3-26.

25. Leeson, P.D.; Springthorpe, B. The influence of drug-like concepts on decision-making in medicinal chemistry. Nat. Rev. Drug Discov. 2007, 6, 881-890.

26. Gleeson, M.P. Generation of a set of simple, interpretable admet rules of thumb. J. Med. Chem. 2008, 51, 817-834.

27. Tarcsay, A.; Nyíri, K.; Keseru, G.M. Impact of lipophilic efficiency on compound quality. J. Med. Chem. 2012, 55, 1252-1260.

28. Hughes, J.D.; Blagg, J.; Price, D.A.; Bailey, S.; Decrescenzo, G.A.; Devraj, R.V.; Ellsworth, E.; Fobian, Y.M.; Gibbs, M.E.; Gilles, R.W.; et al. Physiochemical drug properties associated with in vivo toxicological outcomes. Bioorg. Med. Chem. Lett. 2008, 18, 4872-4875.

29. Taranto, A.G.; Carvalho, P.; Avery, M.A. Qm/qm studies for michael reaction in coronavirus main protease (3cl pro). J. Mol. Graph. Model. 2008, 27, 275-285.

30. Trager, W.; Jensen, J.B. Human malaria parasites in continuous culture. 1976. J. Parasitol. 2005, 91, 484-486.

31. Batista, R.; García, P.A.; Castro, M.A.; Miguel Del Corral, J.M.; Speziali, N.L.; de P Varotti, F.; de Paula, R.C.; García-Fernández, L.F.; Francesch, A.; San Feliciano, A.; et al. Synthesis, cytotoxicity and antiplasmodial activity of novel ent-kaurane derivatives. Eur. J. Med. Chem. 2013, 62, 168-176.

32. Fundação Hemominas-Hemonúcleo Divinópolis. Available online: http://www.hemominas.mg.gov.br (accessed on 1 August 2013).

33. Lambros, C.; Vanderberg, J.P. Synchronization of plasmodium falciparum erythrocytic stages in culture. J. Parasitol. 1979, 65, 418-420. 
34. Carvalho, L.H.; Brandão, M.G.; Santos-Filho, D.; Lopes, J.L.; Krettli, A.U. Antimalarial activity of crude extracts from brazilian plants studied in vivo in plasmodium berghei-infected mice and in vitro against plasmodium falciparum in culture. Braz. J. Med. Biol. Res. 1991, 24, 1113-1123.

35. Carmichael, J.; DeGraff, W.G.; Gazdar, A.F.; Minna, J.D.; Mitchell, J.B. Evaluation of a tetrazolium-based semiautomated colorimetric assay: Assessment of chemosensitivity testing. Cancer Res. 1987, 47, 936-942.

36. Park, J.G.; Kramer, B.S.; Steinberg, S.M.; Carmichael, J.; Collins, J.M.; Minna, J.D.; Gazdar, A.F. Chemosensitivity testing of human colorectal carcinoma cell lines using a tetrazolium-based colorimetric assay. Cancer Res. 1987, 47, 5875-5879.

37. Trott, O.; Olson, A.J. Autodock vina: Improving the speed and accuracy of docking with a new scoring function, efficient optimization, and multithreading. J. Comput. Chem. 2010, 31, 455-461.

38. Stewart, J.J. Optimization of parameters for semiempirical methods v: Modification of nddo approximations and application to 70 elements. J. Mol. Model. 2007, 13, 1173-1213.

Sample Availability: Samples of the compounds are available from the authors.

(C) 2013 by the authors; licensee MDPI, Basel, Switzerland. This article is an open access article distributed under the terms and conditions of the Creative Commons Attribution license (http://creativecommons.org/licenses/by/3.0/). 